\title{
MULTI-OBJECTIVE OPTIMIZATION OF ROAD DESIGN ALTERNATIVES WITH AN APPLICATION OF THE MOORA METHOD
}

\section{Willem Karel M. Brauers}

Faculty of Applied Economics and Institute for

Development Policy and Management,

University of Antwerpen, Birontlaan, 97, B2600

Berchem - Antwerpen, Belgium,

Email: willem.brauers@ua.ac.be.

\section{Friedel Peldschus}

Leipzig University of Applied Sciences, Karl-Liebknecht Street 132, 04277 Leipzig, Germany,

Email: peldschu@fbb.htwk-leipzig.de

\section{Edmundas Kazimieras Zavadskas}

Vilnius Gediminas Technical University, Sauletekio av. 11, Vilnius, LT-10223, Lithuania, Email: edmundas.zavadskas@adm.vtu.lt;

\section{Zenonas Turskis}

Vilnius Gediminas Technical University, Sauletekio av. 11, Vilnius, LT-10223, Lithuania, Email: zenonas.turskis@st.vtu.lt

\begin{abstract}
Multi-objective analysis is a popular tool in many economic, managerial, constructional, etc. problems. The objective of this research is to develop and implement a methodology for multi-objective optimization of multi-alternative decisions in road construction. After a rough overview of multi-objective decision support for assessment of road design alternatives multi-objective optimization with discrete alternatives: MOORA (Multi-Objective Optimization on basis of Ratio Analysis) was selected. This method goes for a matrix of responses of alternatives on objectives, on which ratios are applied. This methodology is applicable to the problems with large numbers of scenarios and objectives. A case study demonstrates the concept of multi-objective optimization of road design alternatives and the best road design alternative is determined
\end{abstract}

\section{KEYWORDS}

Road design, alternative, multi-objective optimization, MOORA method

\section{INTRODUCTION}

Our values, beliefs and perceptions are the force behind almost any decision-making activity. They are responsible for the perceived discrepancy between the present and a desirable state. Contemporary decision problems in construction are characterized by a diversity of structures and processes, hardly commensurable variables, conflicting development objectives and constraints. 
Different stakeholders with different interests and values, make a decision-making process much more complicated. Values are articulated in a goal, which is often the first step in a formal decision process. Each choice represents a decision alternative. In the Multi-Objective Decision-Making (MODM) context, the selection is facilitated by evaluating each choice on the set of objectives.

MODM is also referred as:

- Multi-Criteria Decision Analysis (MCDA)

- Multi-Dimensions Decision-Making (MDDM)

- Multi-Attributes Decision-Making (MADM)

The objectives must be measurable - even if the measurement is performed only at the nominal scale (yes/no; present/absent) and their outcomes must be measured for every decision alternative. Objective outcomes provide the basis for comparison of choices and consequently facilitate the selection of one, satisfactory choice. Therefore, multi-objective techniques seem to be an appropriate tool for ranking or selecting one or more alternatives from a set of available options based on multiple, usually conflicting, objectives. A large number of methods have been developed for solving multi-objective problems [1-3]. MODM frameworks vary from simple approaches, requiring very little information, to methods based on mathematical programming techniques, requiring extensive information on each objective and the preferences of the decision makers. Various classifications of the above-mentioned methods are presented in different publications [46]. But still it is a problem of choosing an appropriate method in a given situation.

Considering the nature of information available to decision makers, MODM can be classified to the following groups [7]:

1) Methods based on quantitative measurements. This group consists of common methods of the multiple criteria utility theory and of some new methods: MOORA, TOPSIS, VIKOR, COPRAS.

2) Methods based on initial qualitative assessment, the results of which later take a quantitative form. This group consists of analytic hierarchy methods (AHP), as well as the methods based of game theory and fuzzy sets.
3) Methods based on quantitative measurements but using a few criteria to compare the alternatives (comparison preference method). This group consists of preference comparison methods: ELECTRE, PROMETEE.

4) Methods based on qualitative data not using a transformation to quantitative variables. This group comprises verbal decision analysis (VDA).

Methods within all these four groups are successfully applied to deal with engineering, including civil engineering, problems [8-22].

The methods of the theory of gambling were used to select a rational variant for road reconstruction [23], to model refurbishment of construction objects [18], to assess compactness of a sustainable city [11] . The AHP method was used to select a rational variant of the design documentation for a large transportation system [15]. Fuzzy sets methods were used to deal with the task related to construction of a water supply pipeline [20].

The ELECTRE-3 method was used to determine preferences when selecting a public transport expansion scenario [12]. The PROMETEE method was used to assess investment projects [19].

A utility problem with different independent objectives and alternative solutions has to be optimized. The utility notion has always been a crucial point for researchers. For us, the utility notion boils down to four problems: the choice of units per objective, the normalization, the optimization and the importance, which is given to an objective. A newly proposed method for multiobjective optimization with discrete alternatives MOORA (Multi-Objective Optimization on basis of Ratio Analysis) [3] tries to satisfy all these preliminary conditions.

An example on evaluating road design illustrates the application of the MOORA method. It is concluded that the MOORA method is ready for practical use and can be a full-fledged method for multiple objective optimisation.

\section{DEFINITION OF THE MOORA METHOD}

The method starts with a matrix of responses of different alternatives on different objectives: 
$x_{i j}$,

with: $x_{i j}$ as the response of alternative $j$ on objective $i, i=1,2, \ldots, n$ as the objectives, $j=1,2, \ldots, m$ as the alternatives.

MOORA goes for a ratio system in which each response of an alternative on an objective is compared to a denominator, which is representative for all alternatives concerning that objective. For this denominator the square root of the sum of squares of each alternative per objective is chosen [24]:

$$
\bar{x}_{i j}=\frac{x_{i j}}{\sqrt{\sum_{j=1}^{m} x_{i j}^{2}}},
$$

with: $x_{i j}$ - response of alternative $j$ on objective $i$,

$j=1,2 \ldots, m ; m$ the number of alternatives, $i=1,2 \ldots, n$; $n$ being the number of objectives,

$\bar{x}_{i j}$ - a dimensionless number representing the normalized response of alternative $j$ on objective $i$. These normalized responses of the alternatives on the objectives belong to the interval $[0 ; 1]$.

For optimization these responses are added in case of maximization and subtracted in case of minimization:

$\bar{y}_{j}=\sum_{i=1}^{i=g} s_{i} \bar{x}_{i j}-\sum_{i=g+1}^{i=n} s_{i} \bar{x}_{i j}$,

with: $i=1,2, \ldots, g$ as the objectives to be maximized,

$i=g+1, g+2, \ldots, n$ as the objectives to be minimized,

$S_{i}$ is introduced as a significance coefficient for the $i$-th objective,

$\bar{y}_{j}-$ is the normalized assessment of alternative $j$ with respect to all objectives.

In this formula linearity concerns dimensionless measures in an interval $[0 ; 1]$. An ordinal ranking of $\bar{y}_{j}$ shows the final preference of the alternatives.

\section{APPLICATION OF THE PROPOSED METHOD FOR EVALUATING ROAD DESIGN ALTERNATIVES}

Roads and bridges have a special role in infrastructure of cities and residential areas. These infrastructure objects are complex engineering facilities and their construction and use requires much special scientific knowledge.

The harmony in the residential environment much depends on the density of road network and the number and capacity of bridges. As of late, the research of general plans [9] and the sustainable development [9-11] and transport flows receives increasing attention. Methods to evaluate citizen opinions [12, 15, and 25], special forecasting methods and decision support systems [14] are being developed for integrated assessment of variants of sustainable urban development.

Constant growth of the number of traffic participants demands expansion of district, national and arterial roads and especially the highway network. Alongside with construction of new roads, adding of more lanes to existing highways plays an exclusive role.

In expansion of the highway network, preparation of good design documentation has an important role. Considering large costs of road construction and widening, it is very important to select as rational solutions as possible. Therefore, it is also necessary to assess accumulated previous experience in order to improve quality and longevity of roads. A special attention must be paid to road safety. Quite a few scientific researches are performed in these fields.

Roads in the Baltic States are affected by varying Northern climate, which causes additional problems of maintenance. In order to improve road safety in winter, additional measures are needed, which damage road surface and have negative effect on the environment. Currently, the road safety on Lithuanian roads is the worst compared to other EU countries. Lithuania ranks the last among all EU countries according to the number of people killed in fatal traffic accidents per one million residents. Ratkevičiūtè et al. [26] provide exhaustive analysis of causes behind the accident rates and offer means to increase the road safety. Kashevskaya [27] and 
Leonovich [28] analyse the problems related to the quality of road infrastructure and, on the basis of the main statements of the road quality management theory, offer a few methods to guarantee high quality road maintenance.

The quality of roads and bridges and flyovers as part of roads depends on the quality of design solutions. The quality of these solutions is determined by knowledge of designers and their ability to apply the newest and the most advanced constructional and technological solutions. Road surfacing was analysed by Ziari and Khabiri [29], Laurinavičius et al. [30], Petkevičius et al. [31], Chang et al. [32], Ziari et al. [33] in order to improve its longevity and maintenance qualities. Bridge constructions were analysed by Frangopol and Liu [34].

When planning to construct roads and determining which road sections need repair of surfacing, the actual condition of road surface must be assessed. However, methods for assessment of road surface and its construction have their limitations. It is easy to notice that some of them are insufficiently precise, others too complex. When assessments are made based on one of the objectives - as is usually the case - the best solutions not always are selected.

In construction of new or renovation of old highways, the following objectives for assessment of design solutions are the most important: cost, duration of construction, longevity, environmental issues, economic validity. The best solution is sought, to achieve the best values of these objectives. However, it is impossible to get all the best values at a time. Thus Multi Objective Decision Making methods are used to deal with such tasks.

Tille and Dumont [35] described how the problem of choice between various alternatives is permanent and crucial in the projects for road infrastructures. The designer must use objective and global methods for proposing to the decision maker an optimal alternative. Only multicriteria decision making methods can be used by the designer as well as possible to considerate this complexity. The use of such methods also makes it possible to bind the objective aspects of the choice, based in particular on technical evaluation of the performance indicators describing the alternatives for each objective, with its subjective aspects, which are the relative consideration of importance of each objective, also called weighting. An evaluation of the various MODM decision making methods was carried out in a real case in Switzerland.

It must be noted that only a few of the mentioned MODM applications are related to dealing with road and bridge construction tasks. Use of MODM methods in other fields of construction is justified. This article-using the MOORA method [3] developed by Brauers - attempts to select a variant for expansion of a highway in Thuringia, Germany, from 4 to 6 lanes. It is attempted to illustrate the rationality of use of MODM methods in road and bridge construction.

\subsection{Assessment alternatives $[23,21]$}

In case study 6 possible alternatives $[23,21]$ of highway design are in consideration:

Variant 1. Construction of a new road by changing the axis and gradients of the highway and using concrete surfacing. Change of gradients requires deep excavations and embankments, i.e. large amount of earthwork. It makes up $70 \mathrm{~m}^{3} / \mathrm{m}$ in average.

Variant 2 . Construction of a new road by changing the axis and gradients of the highway and using asphalt concrete surfacing. Only the surfacing differs compared to Variant 1.

Variant 3. Construction of a new road by changing the axis and retaining the gradients of the highway with concrete surfacing. When the gradients are retained, the amount of earthwork is reduced in Variant 3. It makes up $36.2 \mathrm{~m}^{3} / \mathrm{m}$.

Variant 4. Construction of a new road by changing the axis and retaining the gradients of the highway but with asphalt concrete surfacing. This variant corresponds to Variant 3, only the surfacing differs.

Variant 5. Construction of a new road retaining the axis and the gradient of the highway with concrete surfacing. The amount of earthworks in this variant is similar to that of Variant 3. Only duration differs.

Variant 6. Construction of a new road retaining the axis and the gradient of the highway with asphalt 
concrete surfacing. Variant 6 corresponds to Variant 5 , only the road surfacing differs.

Each alternative (taken from the article by Peldschus and provided in Table 1) is described by five objectives. The following efficiency objectives are calculated to assess the listed variants according to design documentation: price, duration of construction, distance of transportation, noise level and longevity..

Longevity- $x_{1}$ [years]. Longevity is one of the most important objectives in assessment of highway design documentation. The total price much depends on the needed longevity. Thus we have a road while it can be used without expenditures on renovation. Cheap solutions determine large renovation costs and usually become more expensive in the end. For instance, asphalt and concrete surfacing can be compared.

Construction price $-\boldsymbol{x}_{2}\left[10^{6} \epsilon\right]$. One of the main requirements for designing is to strive at as small construction price as possible. But at the same time to guarantee good quality, hardness, to achieve the shortest duration of construction, to guarantee smaller number of detours or changes of direction and to reduce the number of accidents in stages of construction and maintenance. It is important to consider interests of all owners living in neighbouring land plots.

Environment protection $-\boldsymbol{x}_{3}[10 \mathrm{db}(A)]$. Construction of new or renovation of old highways has negative effect on nature. Damage to environment must be minimised during construction. The roads are part of the landscape. They cannot deface the terrain. The amount of earthworks and duration of construction must be minimised during construction. Special methods are being developed for this purpose using the theory of mass service and neural mathematical models [36]. Strategic environment studies are used in the EU. Therefore, special studies must be performed. The effect on flora, fauna, soil, water, air, climate, landscape, existing situation and environment quality must be determined, also considering the demand growing with time. Consumption of natural resources, $\mathrm{CO}_{2}$ emissions and increased noise must be assessed as well.
Economic validity $-\boldsymbol{x}_{4}[100 \mathrm{~m}]$. Economic validity of construction much depends on average distance for soil transportation. Thus when preparing profiles of a road, the distance between the embankment and excavations must be considered. Transportation distances and volumes of transported soil have serious influence on construction costs and duration.

Construction duration- $\boldsymbol{x}_{5}$ [100 Days]. Because reconstruction of highways impedes communication, endeavours are made to reduce the duration of work as much as possible. Speed up requires additional costs and foreseeing of more capacity (labour force and machinery). Thus it must be considered whether it is really necessary. The most rational way is to find such construction variants that could help to reduce construction duration.

Asphalt surfacing is not rigid. It usually consists of an upper layer, the lower layer and the roadbase. Weather and temperature variations during construction can affect the quality and longevity of different variants of asphalt surfacing.

Highways with concrete surfacing have an advantage. This surfacing is rigid, rhealogy depends less on loads and temperature, thus it is stable and does not deform. No tracks appear and elevations emerge due to stopping of heavy vehicles. Besides, concrete roads are less sensitive to the effect of water. The older and more porous is the asphalt, the more serious the effect of water on asphalt concrete solidity. Therefore, the lifetime of concrete roads is from 20 to 30 years and of asphalt concrete road surfacing from 15 to 20 years. Upon expiration of this term the road must be renovated.

The data from Table 1 shows that there are no alternatives where all values of objectives are the best.

\subsection{Ranking of alternatives}

MOORA optimization technique with discrete alternatives was used for ranking of alternatives in the case study. The results of multi-objective analysis are presented in Table 1 .

Normalised values of the first objective are the most varied among themselves (Table 1). If we take the ratio between the optimal and the worst value, this ratio is within the interval $[0.531 ; 0.283]$. Whereas the ratios of other objectives are as follows: second 
$[0.387 ; 0.443]$, third $[0.398 ; 0.419]$, fourth $[0.394$; $0.433]$ and fifth $[0.380 ; 0.442]$. When assessment is based only on the first objective the following rank of alternatives would be obtained (starting with the best alternative): $1 \succ 3 \succ 5 \succ 2 \succ 4 \succ 6$. Whereas based on the second objective we have the following rank of alternatives: $6 \succ 5 \succ 3 \succ 4 \succ 2 \succ 1$ (Table 1). According to MOORA method alternatives ranks as follows: $3 \succ 5 \succ 1 \succ 4 \succ 5 \succ 2$.

\section{CONCLUSIONS}

Based on the case study results was proposed alternatives priority order. This order has proved that the best alternative is construction of a new road by changing the axis and retaining the gradients of the highway with concrete surfacing. The worst one is Construction of a new road by changing the axis and gradients of the highway and using asphalt concrete surfacing.

A case study shows that multi-objective analysis in construction is necessary. Selection of the best alternative can not be based on a single objective.

The case study has proved that the proposed theoretical model was effective in a real life situation and could be successfully applied to solving similar utility problems in construction.

Table 1. The data used in MODM in assessment of highways reconstruction projects: case study Germany (2007)

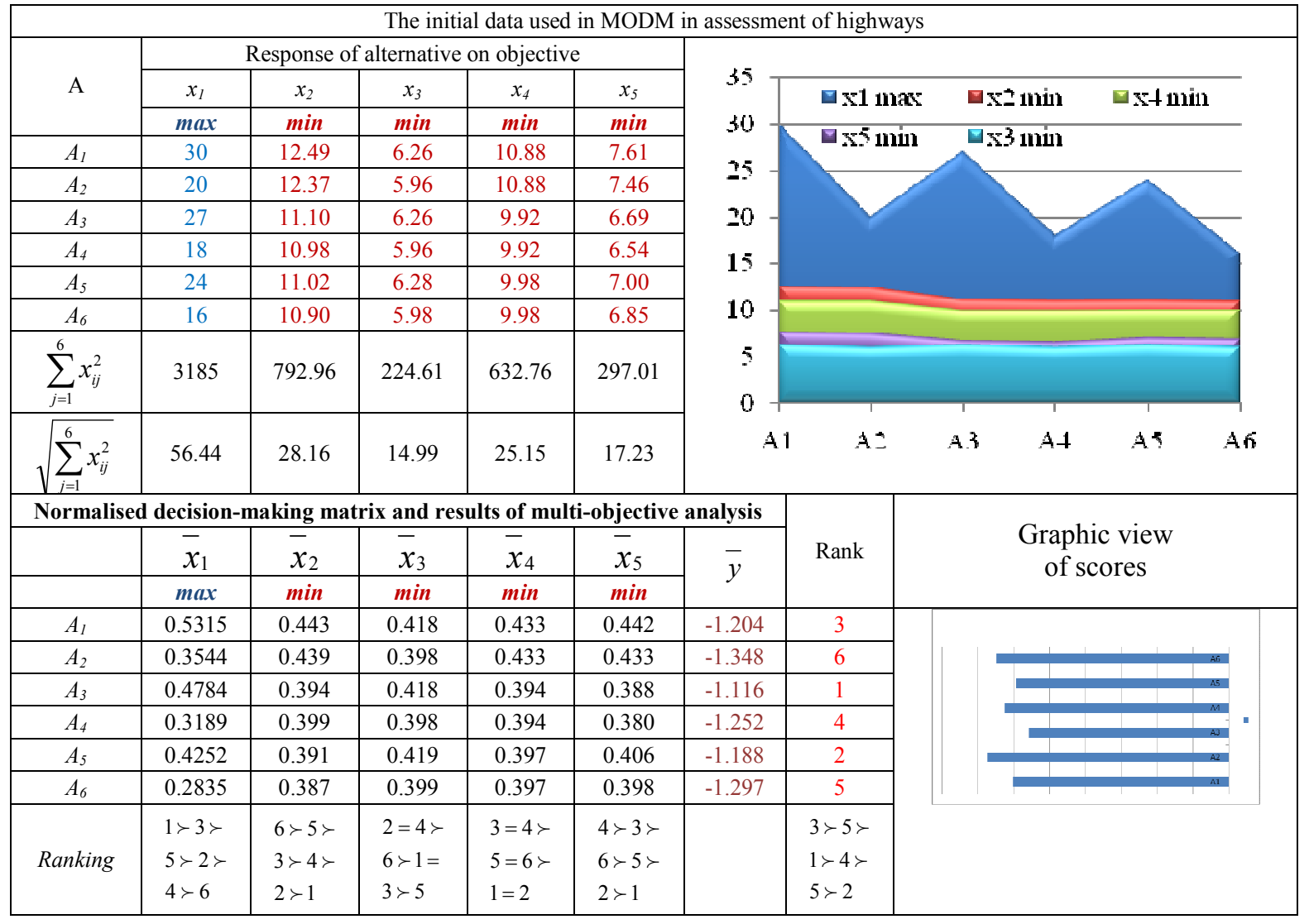




\section{REFERENCES}

[1] Hwang, C.L.; Yoon, K. 1981. Multiple attribute decision making. Methods and applications. Berlin, Heidelberg, New York: Springer - Verlag.

[2] Triantaphyllou, E. 2000. Multi-criteria Decision Making Methods: a Comparative Study. Kluwer Academic Publishers.

[3] Brauers, W. K. 2004. Optimization Methods for a Stakeholder Society. A Revolution in Economic Thinking by Multiobjective Optimization, Kluwer Academic Publishers, Boston.

[4] Roy, B. 1996. Multictriteria Methodology for Decision Aiding. Dortrecht: Kluwer Academic Publishers.

[5] Guitouni, A.; Martel, J. M. 1998. Tentative guidelines to help choosing an appropriate MCDA method. European Journal of Operational Research, Vol. 109, No. 2 501-521.

[6] Greening, L. A.; Bernow, S. 2004. Design of coordinated energy and environmental policies: use of multi-criteria decision-making. Energy Policy, Vol. 32, No.6 721-735.

[7] Ustinovichius, L.; Zavadskas, E. K.; Podvezko, V. 2007. Application of a quantitative multiple criteria decision making (MCDM-1) approach to the analysis of investments in construction. Control and Cybernetics, Vol. 36, No. 1 251-268.

[8] Bardauskiene, D. 2007. The expert's estimates application in the preparation of city general plan. Technological and Economic Development of Economy, Vol. 13, No. 3 223-236.

[9] Zagorskas, J.; Turskis, Z. 2006. Multi-attribute model for estimation of retail centres influence of the city structure. Kaunas city case study. Technological and Economic Development of Economy, Vol. 12, No. 4 347-352.

[10] Šaparauskas, J.; Turskis, Z. 2006. Evaluation of construction sustainability by multiple criteria methods. Technological and Economic Development of Economy, Vol. 12, No. 4 321-326.

[11] Turskis, Z.; Zavadskas, E. K; Zagorskas, J. 2006. Sustainable city compactness evaluation on the basis of GIS and Bayes rule, International Journal of Strategic Property Management, Vol. 10, No. 3 185-207.

[12] Thiel, T. 2006. A proposal of defining participant preferences in a decision aiding process with the participant representing a collective body. Technological and Economic Development of Economy, Vol. 12, No. 3 257-262.
[13] Zavadskas, E. K.; Vilutiene, T. 2006. A multiple criteria evaluation of multi-family apartment block's maintenance contracts: I-Model for maintenance contractor evaluation and determination of its selection criteria. Building and Environment, Vol. 41 621-632.

[14] Kaklauskas, A.; Zavadskas, E. K. 2007. Decision support system for innovation with special emphasis on pollution. International Journal of Environment and Pollution, Vol. 30, Nos. 3/4 518-528.

[15] Su, Ch.-W.; Cheng, M.-Y.; Lin, F.-B. 2006. Simulation-enhanced approach for ranking major transport projects. Journal of Civil Engineering and Management, Vol. 12, No. 4 285-291.

[16] Zavadskas, E. K.; Kaklauskas, A.; Šarka, V. 1994. The new method of multicriteria complex proportional assessment of projects. Technological and Economic Development of Economy, Vol. 1, No. 3 131-139.

[17] Kapliński, O.; Janusz, L. 2006. Three phases of multifactor modelling of construction processes. Journal of Civil Engineering and Management, Vol. 12, No. 2 127-134

[18] Antucheviciene, J.; Turskis, Z.; Zavadskas, E. K. 2006. Modelling renewal of construction objects applying methods of the game theory. Technological and Economic Development of Economy, Vol. 12, No. 4 263-268.

[19] Nowak, M. 2005. Investment projects evaluation by simulation and multiple criteria decision aiding procedure. Journal of Civil Engineering and Management, Vol. 11, No. 3 193-202.

[20] Peldschus, F.; Zavadskas, E. K. 2005. Fuzzy matrix games multi-criteria model for decision-making in engineering. Informatica, Vol. 16, No. 1 107-120.

[21]Zavadskas, E. K.; Kaklauskas, A.; Peldschus, F.; Turskis, Z. 2007. Multi-attribute Assessment of Road Design Solutions by Using the COPRAS Method. The Baltic Journal of Road and Bridge Engineering, Vol. 2, No. 4 195-203.

[22] Kalibatas, D.; Turskis, Z. 2008. Multicriteria evaluation of inner climate by using MOORA method. ISSN 1392 - 124X Information technology and control, Vol. 37, No. $179-83$.

[23] Peldschus, F. 2005. Multiple-criteria analysis in the construction of motorways. Technological and Economic Development of Economy, Vol. 11, No. 1 32-35. 
[24] Van Delft, A.; Nijkamp, P. 1977. Multi-criteria Analysis and Regional Decision-making. M.Nijhoff, Leiden, Nl.

[25] Jakimavičius, M.; Mačerinskienè, A. 2006. A GISbased modelling of vehicles rational routes. Journal of Civil Engineering and Management, Vol. 12, No. 4 303-309.

[26] Ratkevičiute, K.; Čygas, D.; Laurinavičius, A.; Mačiulis, A. 2007. Analysis and evaluation of the efficiency of road safety measures applied to Lithuanian road. The Baltic Journal of Road and Bridge Engineering, Vol. 2, No. 2 81-87.

[27] Kashevskaya, E. 2007. Bases of quality management of construction and repair of highways. The Baltic Journal of Road and Bridge Engineering, Vol. 2, No. 3 101-109.

[28] Leonovich, I.; Kashevskaja, E. 2007. Selection of criteria for process monitoring at the operative level of road quality management. Technological and Economic Development of Economy, Vol.13, No. 2 144-152.

[29] Ziari, H.; Khabiri, M. M. 2007. Interface condition influence on prediction of flexible pavement life. Journal of Civil Engineering and Management, Vol. 13, No. 1 71-76.

[30] Laurinavičius, A.; Oginskas, R. 2006. Experimental research on the development of rutting in asphalt concrete pavements reinforced with geosynthetic materials. Journal of Civil Engineering and Management, Vol. 12, No. 4 311-317.
[31] Petkevičius, E.; Petkevičius, R.; Babickas, R. 2006. Investigation of asphalt concrete pavement quality of Lithuanian highways. The Baltic Journal of Road and Bridge Engineering, Vol. 1, No. 2 71-76.

[32] Chang, J.-R.; Chen, D.-H.; Hung, C.-T. 2005. Selecting preventive maintenance treatments in Texas. Using the technique for order preference by similarity to the ideal solution for specific pavement Study-3 sites. Transportation Research Record. Journal of the Transportation Research Board, No. 1933 62-71.

[33] Ziari, H.; Ameri, M.; Khabiri, M. M. 2007. Resilient behaviour of hot mixed and crack sealed asphalt concrete under repeated leading. Technological and Economic Development of Economy, Vol. 13, No. 1 56-60.

[34] Frangopol, D. M.; Liu, M. 2007. Maintenance and management of civil infrastructure based on condition, safety, optimization and life-cycle cost. Structure and Infrastructure Engineering, Vol. 3, No. $129-41$.

[35] Tille, M; Dumont, A-G. 2003. The multicriteria decision making methods : a practical tool for design a sustainability road infrastructure. Proceedings of the XXIInd PIARC World Road Congress. World Road Association - PIARC.

[36] Schabovicz, K.; Hola, B. 2007. Mathematical-neural model for assessing productivity of earthmoving machinery. Journal of Civil Engineering and Management, Vol. 13, No. 1 47-54. 